\title{
Long-Term Quality of Life Outcomes After Laparoscopic Sleeve Gastrectomy and Roux-en-Y Gastric Bypass-a Comparative Study
}

\author{
Cristina Fiorani ${ }^{1}$ (D) Sophie R. Coles ${ }^{1} \cdot$ Myutan Kulendran ${ }^{1} \cdot$ Emma Rose McGlone ${ }^{1} \cdot$ Marcus Reddy ${ }^{1} \cdot$ Omar A. Khan $^{1}$
}

Received: 13 June 2020 /Revised: 4 October 2020 / Accepted: 6 October 2020 / Published online: 16 October 2020

(C) The Author(s) 2020

\begin{abstract}
Roux-en-Y gastric bypass (RYGB) and sleeve gastrectomy (SG) have been shown to improve metabolic comorbidities as well as quality of life $(\mathrm{QoL})$ in the obese population. The vast majority of previous studies have investigated the metabolic effects of bariatric surgery and there is a dearth of studies examining long-term QoL outcomes post bariatric surgery. The outcomes of 43 patients who underwent bariatric surgery were prospectively assessed, using BAROS questionnaires to quantify QoL and metabolic status pre-operatively, at 1 year and at 8 years. Total weight loss and comorbidity resolution were similar between RYGB and SG. The RYGB cohort experienced greater QoL improvement from baseline and had higher BAROS scores at 8 years. RYGB may provide more substantial and durable long-term benefits as compared to SG.
\end{abstract}

Keywords Bariatric surgery $\cdot$ BAROS questionnaire $\cdot$ Sleeve gastrectomy $\cdot$ Gastric bypass $\cdot$ Comorbidity $\cdot$ Weight loss

\section{Introduction}

Roux-en-Y gastric bypass (RYGB) and sleeve gastrectomy (SG) are well-established treatments for morbid obesity and have demonstrated particular efficacy in improving metabolic conditions such as type 2 diabetes mellitus (T2DM) and hypertension [1]. However in addition to their metabolic effects, there is evidence that these operations improve quality of life $(\mathrm{QoL})$

Omar A. Khan

Omar.khan7000@gmail.com

Cristina Fiorani

fiorani.cristina@gmail.com

Sophie R. Coles

sophiecoles92@googlemail.com

Myutan Kulendran

Myutan4@gmail.com

Emma Rose McGlone

ermcglone@gmail.com

Marcus Reddy

Marcusreddy@doctors.org.uk

1 St George's University Hospital, Blackshaw Road Tooting,, London SW17 0QT, UK via both weight loss-dependent and weight loss-independent effects [2]. To date, most studies comparing these procedures have focussed on metabolic effects as opposed to comparative QoL outcomes [3]. In addition, there are very limited long-term data on QoL outcomes post bariatric surgery.

The aim of this prospective study was to compare pre-operative, short-term and long-term QoL, weight loss and metabolic status in a consecutive cohort of patients undergoing RYGB and SG.

\section{Methods}

Between May and October 2010, a total of 136 consecutive adult patients underwent RYGB $(n=92)$ or SG $(n=44)$ at St George's Hospital, London (a tertiary referral centre for bariatric surgery) by three specialist bariatric consultant surgeons. Allocation to SG or RYGB was made by a multidisciplinary team based on patient and surgeon preferences. Surgery was performed in a standardised fashion-RYGB involved a formation of a small proximal gastric pouch with a biliopancreatic limb length of $60 \mathrm{~cm}$ and an alimentary limb of $100 \mathrm{~cm}$. The SG was constructed in an antral-sparing fashion over a $34 \mathrm{Fr}$ Bougie. 


\section{Data Collection}

The Bariatric Analysis and Reporting Outcome system (BAROS) was utilised as a validated tool to assess QoL and metabolic outcomes [3] (Fig. 1). For these purposes of this scoring system, resolution of T2DM was defined using the American Diabetes Association criteria (fasting blood glucose $<7.0 \mathrm{mmol} / \mathrm{L}$ and $\mathrm{HbAlc}<6.5 \%$ ). Improvement of any comorbidity was defined as a reduction in the number of medications required.

Patients underwent pre-operative and 1-year post-operative assessments with face-to-face clinic appointments. At 8 years after surgery, the patients were contacted by post, telephone and email, and following contact with the patient, a telephone consultation was arranged. In order to increase the number in the cohort, non-responders were recontacted after 1 month by post, telephone and email (with the patients' registered general practitioners contacted to check the accuracy of the patients' contact details).

\section{Analysis}

Of the initial cohort, 43 patients $(\mathrm{RYGB}=32, \mathrm{SG}=11) \mathrm{com}$ pleted the BAROS questionnaire at all three time points; and this group forms the basis of our study.

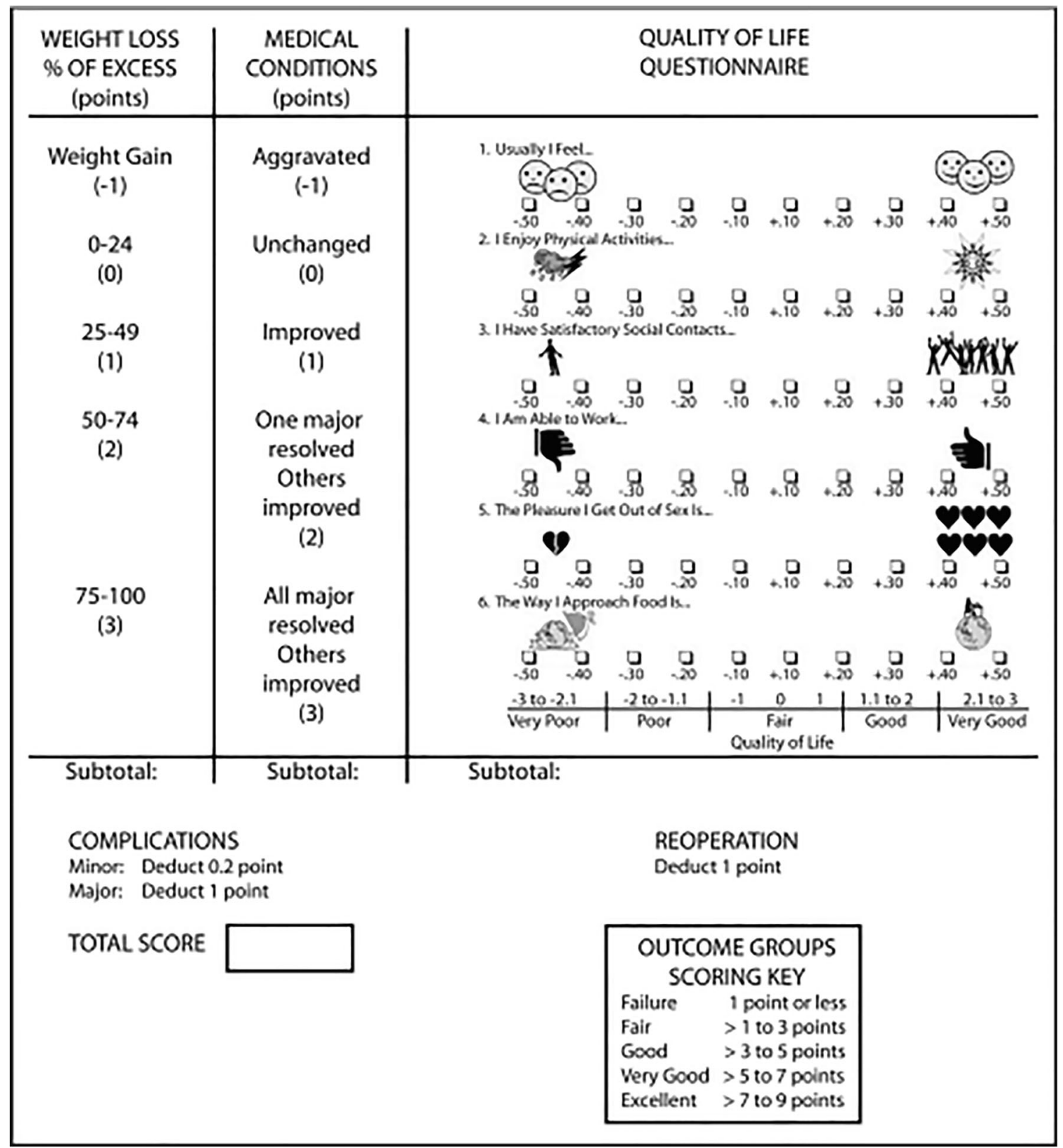

Fig. 1 Summary of BAROS scoring system 
Data were expressed as mean \pm standard error of the mean (SEM) with differences assessed using Student $t$ tests or Mann-Whitney as indicated. Categorical data are presented as frequencies and percentages, with differences assessed using Fisher's exact test or chi-square test as appropriate.

\section{Results}

\section{Demographic Data}

There were no significant differences in the mean preoperative body mass index (BMI) or comorbidities between the two groups (Table 1).

\section{Quality of Life}

Patients undergoing RYGB had poorer pre-operative QoL in all domains as compared to SG (Table 1).

\section{Peri-operative Complications}

There were no major complications (Clavien-Dindo grade 3 or higher), and no patients underwent revisional surgery during the follow-up period.

\section{Weight Loss}

There was no significant difference in weight loss parameters between the two groups (Table 2).

\section{Co-morbidities}

Changes in pre-operative comorbidities 8 years after surgery are displayed in Table 2.

Of 11 patients with pre-operative T2DM in the RYGB cohort, six of whom required insulin, two experienced resolution of their T2DM and four no longer required insulin; of four patients with pre-operative T2DM in the SG cohort, none of whom required insulin, two resolved.

\section{Quality of Life Changes}

Detailed analysis of QoL scores revealed that all components of the QoL score were significantly improved at 1- and 8-year follow-up in the RYGB cohort as compared to pre-operative scores.

In the SG cohort, there were significant improvements only in self-esteem $(p=0.03)$ and social activity $(p=0.01)$ scores at 1-year follow-up as compared to pre-operative scores.

At 8 years, only social activity scores remaining improved $(p=0.03)$.

Despite patients undergoing RYGB having worse QoL scores at baseline, QoL scores at 1 year between the two
Table 1 Demographic data, BMI, comorbidities and pre-operative QoL

\begin{tabular}{|c|c|c|c|c|}
\hline & & $\begin{array}{l}\text { RYGB } \\
n=32\end{array}$ & $\begin{array}{l}\text { SG } \\
n=11\end{array}$ & $p$ \\
\hline Age (years) & & $47(8.3)$ & $42.5(3.62)$ & 0.21 \\
\hline $\operatorname{Sex}\left(F^{\mathrm{a}} / \mathrm{M}^{\mathrm{b}}\right)$ & & $27 / 5$ & $10 / 1$ & 1 \\
\hline Pre-op BMI ${ }^{\mathrm{c}}$ & & $45.6(0.81)$ & $47(1.84)$ & 0.43 \\
\hline Diabetes & & 11 & 4 & 1 \\
\hline Hypertension & & 15 & 2 & 0.15 \\
\hline $\mathrm{OSA}^{\mathrm{d}}$ & & 7 & 2 & 1 \\
\hline Dyslipidemia & & 9 & 2 & 0.70 \\
\hline GERD $^{\mathrm{e}}$ & & 14 & 6 & 0.73 \\
\hline \multirow[t]{7}{*}{ Baseline QoL scores based on BAROS [3] } & Self-esteem & $-0.30(0.03)$ & $-0.05(0.06)$ & $<0.001$ \\
\hline & Physical activity & $-0.25(0.04)$ & $0.02(0.09)$ & $<0.001$ \\
\hline & Social activity & $-0.23(0.04)$ & $-0.03(0.10)$ & 0.05 \\
\hline & Work conditions & $-0.18(0.05)$ & $0.12(0.11)$ & 0.01 \\
\hline & Sexual activity & $-0.25(0.03)$ & $0.03(0.08)$ & $<0.001$ \\
\hline & Relationship to food & $-0.14(0.04)$ & $0.08(0.04)$ & 0.01 \\
\hline & Total BAROS & $-1.35(0.14)$ & $0.17(0.32)$ & $<0.001$ \\
\hline
\end{tabular}

Values are expressed as mean (s.e.m.)

${ }^{\mathrm{a}} \mathrm{F}$ female, ${ }^{\mathrm{b}} \mathrm{M}$ male, ${ }^{\mathrm{c}} \mathrm{BMI}$ body mass index, ${ }^{\mathrm{d}}$ OSA obstructive sleep apnea, ${ }^{\mathrm{e}}$ GERD gastro-oesophageal reflux disease 
Table 2 Weight loss and changes in comorbidities and in QoL outcomes post RYGB and SG

\begin{tabular}{|c|c|c|c|c|}
\hline Weight & & RYGB & SG & $p$ \\
\hline \multirow[t]{4}{*}{1 year } & $\mathrm{BMI}^{\mathrm{a}}$ & $37.7(0.79)$ & 39.7 (1.87) & 0.27 \\
\hline & Change in $\mathrm{BMI}^{\mathrm{a}}$ & $7.9(0.46)$ & $7.3(0.75)$ & 0.54 \\
\hline & Total weight loss (\%) & $17.2(0.97)$ & $15.7(1.57)$ & 0.42 \\
\hline & $\operatorname{EBMIL}^{\mathrm{b}}(\%)$ & $39.0(2.35)$ & $35.1(3.86)$ & 0.40 \\
\hline \multirow[t]{4}{*}{8 years } & $\mathrm{BMI}^{\mathrm{a}}$ & $32(0.99)$ & $33.6(1.75)$ & 0.43 \\
\hline & Change in $\mathrm{BMI}^{\mathrm{a}}$ & $13.6(0.94)$ & $13.4(2.23)$ & 0.93 \\
\hline & Total weight loss (\%) & $29.2(1.87)$ & $27.7(4.16)$ & 0.69 \\
\hline & $\operatorname{EBMIL}^{\mathrm{b}}(\%)$ & $66.8(4.65)$ & $59.4(8.41)$ & 0.43 \\
\hline Quality of life scores & & RYGB & SG & $p$ \\
\hline \multirow[t]{7}{*}{1 year } & Self-esteem & $0.28(0.03)$ & $0.24(0.07)$ & 0.49 \\
\hline & Physical activity & $0.19(0.04)$ & $0.20(0.07)$ & 0.88 \\
\hline & Social activity & $0.25(0.08)$ & $0.22(0.07)$ & 0.65 \\
\hline & Work conditions & $0.18(0.05)$ & $0.25(0.07)$ & 0.44 \\
\hline & Sexual activity & $0.10(0.06)$ & $0.13(0.10)$ & 0.80 \\
\hline & Relationship to food & $0.28(0.04)$ & $0.27(0.08)$ & 0.98 \\
\hline & Total & $1.27(0.18)$ & $1.31(0.40)$ & 0.92 \\
\hline \multirow[t]{7}{*}{8 year } & Self-esteem & $0.22(0.04)$ & $0.11(0.07)$ & 0.19 \\
\hline & Physical activity & $0.10(0.05)$ & $0.02(0.07)$ & 0.37 \\
\hline & Social activity & $0.25(0.05)$ & $0.25(0.07)$ & 0.96 \\
\hline & Work conditions & $0.29(0.06)$ & $0.34(0.09)$ & 0.68 \\
\hline & Sexual activity & $0.09(0.06)$ & $-0.03(0.12)$ & 0.35 \\
\hline & Relationship to food & $0.25(0.05)$ & $0.24(0.07)$ & 0.88 \\
\hline & Total & $1.24(0.21)$ & $0.93(0.30)$ & 0.45 \\
\hline Comorbidity & & RYGB & SG & $p$ \\
\hline \multirow{5}{*}{$\begin{array}{l}\text { Resolved or improved } \\
n(\%)\end{array}$} & $\mathrm{T}_{2} \mathrm{DM}^{\mathrm{c}}$ & $6(55)$ & $2(50)$ & $\mathrm{n} / \mathrm{a}$ * \\
\hline & Hypertension & $6(40)$ & 0 & $\mathrm{n} / \mathrm{a}^{*}$ \\
\hline & $\mathrm{OSA}^{\mathrm{d}}$ & $5(71)$ & $1(50)$ & $\mathrm{n} / \mathrm{a}^{*}$ \\
\hline & Dyslipidemia & $4(44)$ & $1(50)$ & $\mathrm{n} / \mathrm{a}^{*}$ \\
\hline & GERD $^{\mathrm{e}}$ & $5(36)$ & 0 & $\mathrm{n} / \mathrm{a}$ * \\
\hline
\end{tabular}

Values are expressed as mean (s.e.m.)

${ }^{a} B M I$ body mass index, ${ }^{\mathrm{b}}$ EBMIL excess body mass index loss, ${ }^{\mathrm{c}} T 2 D M$ type 2 diabetes mellitus, ${ }^{\mathrm{d}}$ OSA obstructive sleep apnea syndrome, ${ }^{\mathrm{e}}$ GERD gastro-oesophageal reflux disease

*n/a non-applicable — due to the small numbers $p$ value was not calculated groups were comparable. RYGB group achieved a greater improvement in QoL outcomes at 8 years (Table 2).

\section{Overall BAROS Scores}

Mean BAROS scores were similar between the two groups at 1 year $(3.49 \pm 0.24$ vs $3.49 \pm 0.51 ; p=1.00)$ but were significantly higher in the RYGB group at 8 years $(2.64 \pm 0.32$ vs. $1.47 \pm 0.36 ; p=0.02$ ).

\section{Discussion}

Given obesity is a chronic, multifaceted disease, there is a need to evaluate long-term QoL outcomes following bariatric surgery. This is one of the first prospective studies reporting longer-term QoL outcomes of patients undergoing RYGB and SG. Our results demonstrate good QoL, weight loss and metabolic outcomes at 1 and 8 years, with none of the patients requiring emergency or revision surgery (as compared to reported re-operative rates of up to 7\% [4]). It should be noted, however, that the final BAROS scores in our cohort appear to be less favourable than those described in the few previously published longer-term studies evaluating BAROS outcomes after RYGB and SG [5-9]. This finding may be partly due to the shorter follow-up in these studies and that the cohort in these studies were less obese and hence would be expected to have higher BAROS scores at follow-up [8].

Long-term weight loss was similar between RYGB and $\mathrm{SG}-\mathrm{a}$ finding consistent with previous randomised studies 
$[1,2]$. Comorbidity resolution rates also appeared broadly comparable - although the very small numbers preclude statistical analysis and hence definitive conclusions on this subject. With regard to quality of life, scores improved in all domains after RYGB at 8-year follow-up, compared to improvement in only social activity scores in the SG cohort only. Although QoL and overall BAROS scores at 1 year were similar between the two cohorts, the RYGB cohort had higher scores at 8 years. These results suggest that RYGB has both a more profound and a more durable effect on quality of life than SG.

We acknowledge that the high incidence of loss to follow-up (though comparable to studies with similar duration [10]) and the relatively small size of our cohort does limit the strength of the conclusions we can draw. In particular, we were unable to analyse any potential interactions between reduction in body weight, resolution of co-morbidities and improvement in self-reported QoL. In addition, we accept that this was not a randomised control study; however, the fact that RYGB cohort group had more adverse initial clinical features but still had better long-term outcomes in fact adds validity to our conclusions on the relative merits of the two procedures.

\section{Conclusions}

RYGB appears to provide more substantial and durable longterm benefits for morbidly obese patients as compared to SG particularly in terms of QoL improvements. These results require validation in a larger study.

Acknowledgements The authors gratefully acknowledge the contributions of Mr. Andrew Wan and Mr. Georgios Vasilikostas in the clinical care of these patients.

\section{Compliance with Ethical Standards}

Conflict of Interest The authors declare that they have no conflict of interest.

Ethical Approval This study has been approved by the appropriate institutional ethics committee and has been performed in accordance with the ethical standards as laid down in the 1964 Declaration of Helsinki and its later amendments or comparable ethical standards.

Informed Consent Statement Informed consent was obtained from all individual participants included in the study.

Open Access This article is licensed under a Creative Commons Attribution 4.0 International License, which permits use, sharing, adaptation, distribution and reproduction in any medium or format, as long as you give appropriate credit to the original author(s) and the source, provide a link to the Creative Commons licence, and indicate if changes were made. The images or other third party material in this article are included in the article's Creative Commons licence, unless indicated otherwise in a credit line to the material. If material is not included in the article's Creative Commons licence and your intended use is not permitted by statutory regulation or exceeds the permitted use, you will need to obtain permission directly from the copyright holder. To view a copy of this licence, visit http://creativecommons.org/licenses/by/4.0/.

\section{References}

1. Salminen P, Helmiö M, Ovaska J, et al. Effect of laparoscopic sleeve gastrectomy vs laparoscopic roux-en-Y gastric bypass on weight loss at 5 years among patients with morbid obesity: the SLEEVEPASS randomized clinical trial. Jama. 2018;319(3):24154. https://doi.org/10.1001/jama.2017.20313.

2. Peterli R, Wölnerhanssen B, Peters T, et al. Effect of laparoscopic sleeve gastrectomy vs laparoscopic roux-en-Y gastric bypass on weight loss in patients with morbid obesity: the SM-BOSS randomized clinical trial. Jama. 2018;319(3):255-65. https://doi.org/10. 1001/jama.2017.20897.

3. Oria HE, Moorehead MK. Bariatric analysis and reporting outcome system (BAROS). Obes Surg. 1998;8(5):487-99. https://doi.org/ 10.1381/096089298765554043.

4. Khan OA, McGlone ER, Maynard W, et al. Single-stage conversions from failed gastric band to sleeve gastrectomy versus Rouxen-Y gastric bypass: results from the United Kingdom National Bariatric Surgical Registry. Surg Obes Relat Dis. 2018;14(10): 1516-20. https://doi.org/10.1016/j.soard.2018.06.017.

5. Bobowicz M, Lehmann A, Orlowski M, et al. Preliminary outcomes 1 year after laparoscopic sleeve gastrectomy based on bariatric analysis and reporting outcome system (BAROS). Obes Surg. 2011;21(12):1843-8. https://doi.org/10.1007/s11695-011-0403-4.

6. D'Hondt M, Vanneste S, Pottel H, et al. Laparoscopic sleeve gastrectomy as a single-stage procedure for the treatment of morbid obesity and the resulting quality of life, resolution of comorbidities, food tolerance, and 6-year weight loss. Surg Endosc. 2011;25(8): 2498-504. https://doi.org/10.1007/s00464-011-1572-x.

7. Suter M, Donadini A, Romy S, et al. Laparoscopic Roux-En-Y gastric bypass: significant long-term weight loss, improvement of obesity-related comorbidities and quality of life. Ann Surg. 2011;254(2):267-73. https://doi.org/10.1097/SLA. 0b013e3182263b66.

8. Harakeh AB, Larson CJ, Mathiason MA, et al. BAROS results in 700 patients after laparoscopic Roux-en-Y gastric bypass with subset analysis of age, gender, and initial body mass index. Surg Obes Relat Dis. 2011;7(1):94-8. https://doi.org/10.1016/j.soard.2010.09. 020 .

9. McGlone ER, Bond A, Reddy M, et al. Super-obesity in the elderly: is bariatric surgery justified? Obes Surg. 2015;25(9):1750-5. https://doi.org/10.1007/s11695-015-1776-6.

10. Gulliford MC, Booth HP, Reddy M, et al. Effect of contemporary bariatric surgical procedures on type 2 diabetes remission. A population-based matched cohort study. Obes Surg. 2016;26(10): 2308-15. Published online 2016 Feb 27. https://doi.org/10.1007/ s11695-016-2103-6.

Publisher's Note Springer Nature remains neutral with regard to jurisdictional claims in published maps and institutional affiliations. 